\title{
The compliance with and knowledge about radiation protection in operating room personnel: a cross-sectional study with a questionnaire
}

\author{
Thorsten Jentzsch $^{1} \cdot$ Christiane M. Pietsch $^{1,2} \cdot$ Brigitte Stigler $^{1} \cdot$ Leonhard E. Ramseier $^{3}$. \\ Burkhardt Seifert $^{4}$. Clément M. L. Werner ${ }^{1}$
}

Received: 19 March 2015/Published online: 19 June 2015

(C) Springer-Verlag Berlin Heidelberg 2015

\begin{abstract}
Introduction Radiation protection is becoming more important with an ongoing increase in radiation exposure due to the use of $\mathrm{X}$-rays in minimally invasive procedures in orthopaedic and trauma surgeries. However, sufficient education in medical physics and radiation protection can often be improved.

Materials and methods A questionnaire consisting of four questions about personal data and ten questions about radiation protection was distributed to lead consultants, consultants, residents, medical students, and medical technical assistants at two institutions, a level 1 trauma center and a children's hospital.

Results This study consisted of 83 participants. The compliance with radiation protection, i.e., usage of a dosimetry, an apron, and a thyroid shield on a regular basis was only seen in $54 \%$. Participants from the trauma center wore a dosimeter and thyroid shield significantly more often. The regular use of a
\end{abstract}

Electronic supplementary material The online version of this article (doi:10.1007/s00402-015-2257-z) contains supplementary material, which is available to authorized users.

Thorsten Jentzsch

thorsten.jentzsch@usz.ch; thorsten.jentzsch@gmail.com

1 Division of Trauma Surgery, Department of Surgery, University Hospital Zürich, University of Zürich, Rämistrasse 100, 8091 Zürich, Switzerland

2 Clinic for Orthopaedic and Trauma Surgery, Kantonsspital Baden, Baden, Switzerland

3 Orthopaedic Division, Department of Surgery, University Children's Hospital Zürich, Zürich, Switzerland

4 Department of Biostatistics, Epidemiology, Biostatistics and Prevention Institute, University of Zürich, Zurich, Switzerland thyroid shield differed significantly between job positions. It was observed in $80 \%$ of students, but only $15 \%$ of technical assistants. Only $65 \%$ of all knowledge questions were answered correctly. There was a discrepancy between incorrectly answered knowledge questions (35\%) and those marked as uncertain $(20 \%)$. Different job positions did not have an impact on the answers to the questions in most instances.

Conclusions The compliance with and the knowledge about radiation protection seems to be unnecessarily low in trauma physicians and technical assistants. The discrepancy in falsely answered questions and those marked as uncertain may suggest that participants may overestimate their knowledge about radiation protection, which is potentially harmful due to the increased radiation exposure. Therefore, we advocate a quick and valuable training of trauma surgeons and medical staff addressing the important preventive measures, some of which are illustrated in the present study. These consist of wearing dosimetry and protection devices, reduction in X-ray duration, preferably antero-posterior $\mathrm{C}$-arm positioning with the image intensifier close to the patient and the surgeon, maximal distance, collimation, and increased voltage. Furthermore, the use of visual feedback on complex and potentially hazardous radiation facts may be useful for training purposes.

Study design Cross-sectional study with a questionnaire.

Keywords Radiation protection - X-ray - Compliance . Knowledge · Operating room personnel · Trauma surgery · Questionnaire · Training

\section{Introduction}

There is an ongoing increase in usage of X-rays and exposure to radiation, which is especially true for orthopaedic and trauma surgeries, where minimally invasive surgical 
techniques including real-time visualization have become more popular $[1,2]$. However, trauma surgeons and medical technical assistants are often insufficiently educated in medical physics and the occupational prevention of radiation exposure remains inconsistent [1, 3, 4]. This often results in unnecessarily high radiation exposure, which could be prevented with proper, easy, and quick training.

Radiation protection measures were not implemented until about 20 years after Röntgen's discovery in 1895 [5, 6], after an increasing awareness of the harmfulness and carcinogenic potential of X-rays became apparent [7]. In general, radiation protection can be accomplished through measures of mechanical, barrier, and span nature [8]. Mechanical measures involve the direction of beams, while barriers refer to protective aprons and span indicates the distance between surgeons and X-ray machines. These principles offer guidance on radiation protection and are publically conveyed through the International Commission on Radiological Protection (ICRP) in Europe and the National Council on Radiation Protection and Measurements (NCRP) in the United States [6, 9]. Courses about radiation protection are even mandatory for physicians in some parts of the world [10]. In general, naturally occurring radiation exposure ranges around 3 milli $(\mathrm{m})$ Sievert (Sv) per year and mainly includes cosmic, terrestrial, and radon exposure [1]. Particularly, cosmic radiation ranges around $0.24 \mathrm{mSv}$ per year, a 5 -h flight is accompanied by radiation exposure with $0.025 \mathrm{mSv}$, and flight crews average up to $6 \mathrm{mSv}$ per year [1, 11]. In physicians, partial body radiation such as the hands should not exceed $500 \mathrm{mSv}$ per year $[1,9$, $12,13]$. Radiation to the thyroid gland and eyes should even stay below 300 and $150 \mathrm{mSv}$ per year. For example, a surgeon is exposed to a radiation dose of $0.05 \mathrm{mSv}$ per minute at a distance of approximately $0.5 \mathrm{~m} \mathrm{[14]}$.

Technically, there are two types of X-rays. The primary radiation beam is located between the $\mathrm{X}$-ray generator and the image intensifier [1] (Fig. 1). It delivers X-rays according to the different penetrations of various tissues. The scattered radiation arises from patients or objects within the path of the X-ray beam (Fig. 2). X-ray images are generated at the image intensifier, where a fluorescent screen of a vacuum tube absorbs X-ray beams, which leads to a conversion of a latent photograph into a photographic image and, ultimately, an electronic image through a photocathode. The equivalent dose ( $\mathrm{Sv}$ ) determines radiation exposure and can be calculated using the absorbed dose [Gray $(\mathrm{Gy})=$ Joule $(\mathrm{J}) /$ kilogram $(\mathrm{kg})]$ of body tissues multiplied by type- and energy-dependent radiation weighting factor. Weighting factors are determined on a regular basis in order to characterize radiosensitivity of different body tissues [9]. Glands (0.2) have a rather high weighting factor, while most solid organs (0.05) and the skin display a rather low weighting factor.

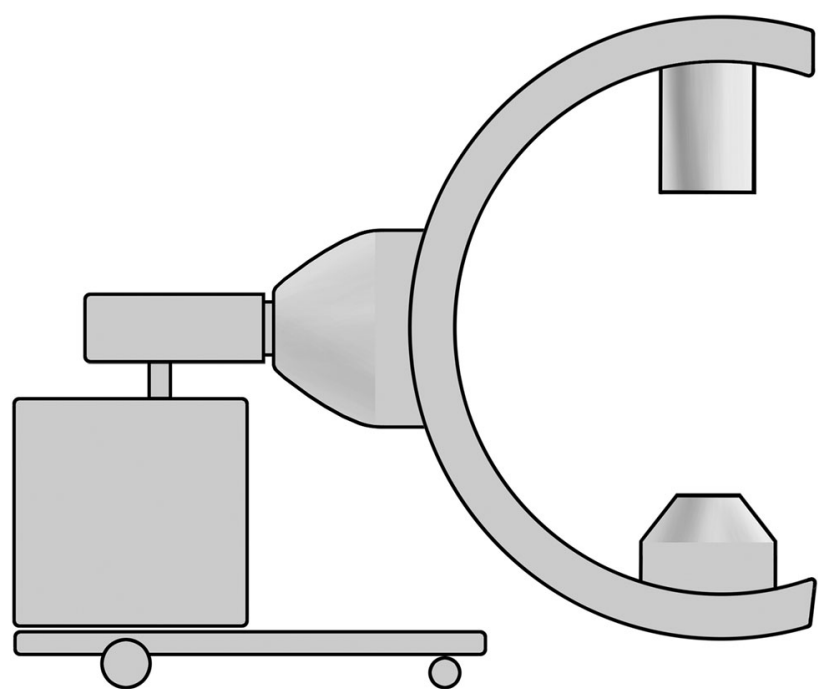

Fig. 1 Example of an X-ray C-arm with the image intensifier (top) and X-ray generator (bottom)

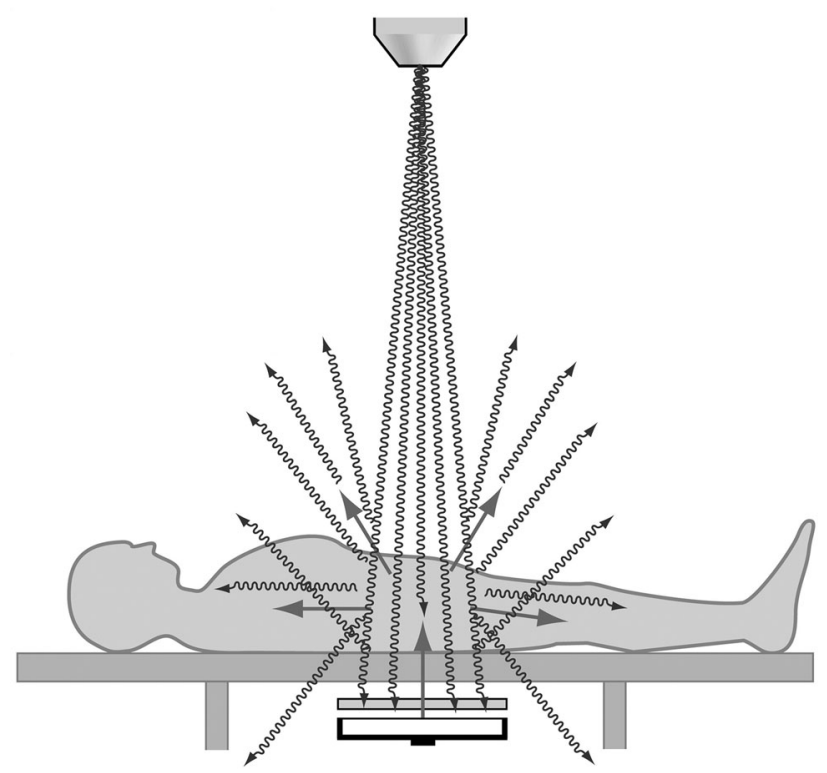

Fig. 2 Scattered radiation from an X-ray beam

The purpose of the present study was to test the existing compliance with and knowledge about radiation protection through a questionnaire and provide illustrated, practical guidelines about radiation protection for trauma surgeons.

\section{Materials and methods}

A questionnaire consisting of one question about the job position, three questions about the compliance with radiation protection, and ten questions about the knowledge 
regarding radiation protection was developed (Supplement 1). General questions asked about (a) the hospital affiliation, (b) job position, (c) dosimetry (whether or not a badge was worn), and (d) use of protective devices such as aprons and thyroid shields. Specific questions consisted of the different radiation exposures with varying (I-III) horizontal and vertical C-arm positions (Figs. 3, 4, 5), (IV) anteroposterior and lateral views, (V) eyes and hands, (VI) type of surgery, i.e., instrumentation of the spine or nailing of the femur, (VII) voltage and current, (VIII) collimation, (IX) distance, and (X) maximal partial body radiation exposure.

Participants consisted of available lead consultants, consultants, residents, medical students, and medical technical assistants at two institutions, a level 1 trauma center and an orthopaedic division of a children's hospital, where X-rays are commonly used. Participants were asked to complete the survey in the presence of a supervisor in order to avoid cheating. Moreover, they were asked to mark either " $A$ " or " $B$ " with regard to the worse radiation exposure, and, "C" if they were uncertain about their answer. A waiver for this study was obtained from the local ethics committee allotted. All voluntary participants gave informed consent to their participation in this study and publishing of their anonymous data.

Data are presented as the number of participants with percentages. Groups were compared using the Chi-square test with exact $p$ values. Two-sided $p$ values less than 0.05 were considered statistically significant. All analyses were performed with IBM SPSS Statistics, Version 21.0 (IBM Corp., Armonk, NY, USA).

\section{Results}

This study consisted of 83 participants, whereof 54 (65\%) were recruited from a level 1 trauma center and $29(35 \%)$ came from the children's hospital. There were nine $(11 \%)$ lead consultants, 20 (24\%) residents, five $(6 \%)$ students, and $21(25 \%)$ technical assistants. No differences were found between the job positions of the participants of the two hospitals $(p=0.79)$.

Surprisingly, the compliance with radiation protection, i.e., $\geq 50 \%$ usage of a dosimetry, an apron, and a thyroid shield, was only found in $54 \%$ (Table 1). Furthermore, the participants from the trauma center wore a dosimeter and thyroid shield significantly more often $(p=0.028$ and $p=0.006$, respectively), but there were no differences regarding the use of aprons. Moreover, the job position was associated with significant differences in the use of a thyroid shield, whereby $80 \%$ of students, $43 \%$ of residents, $30 \%$ of consultants, $22 \%$ of lead consultants, and only $15 \%$ of technical assistants wore a thyroid shield $\geq 50 \%$ of the time $(p=0.047)$. No differences were found for the usage of a dosimeter or an apron.

The knowledge questions about radiation protection were only answered correctly by $65 \%$ of all participants (Table 2). Questions containing a text were answered significantly better than questions with a picture $(p=0.010)$. No differences between the two hospitals were found for almost all $(90 \%)$ knowledge questions about radiation protection, while only one (10\%) question about the vertical position of the X-ray machine was answered significantly better by the participants of the trauma center
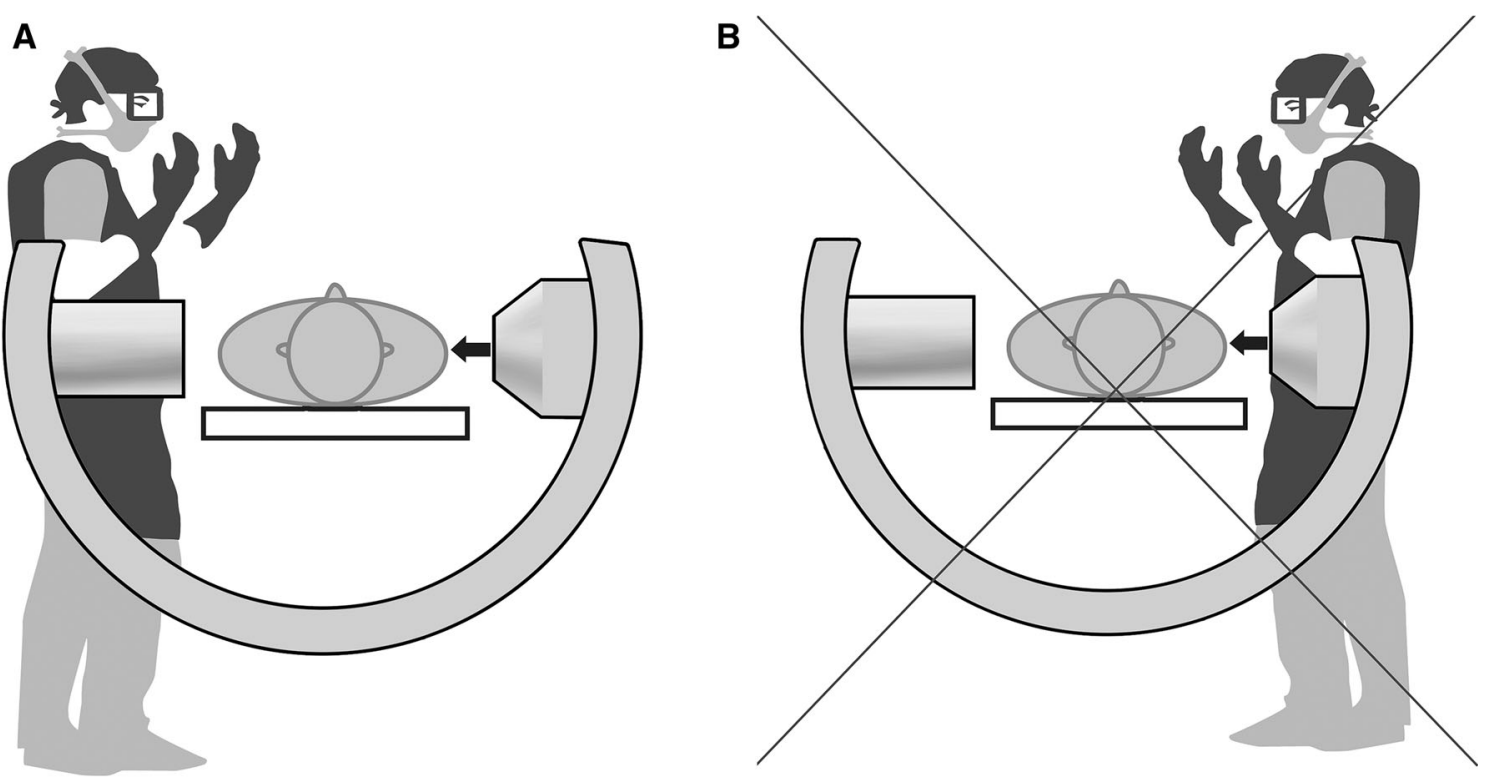

Fig. 3 a Horizontal positioning of the image intensifier and the X-ray tube. The correct positioning with the image intensifier on the surgeon's side is shown in $\mathbf{a}$, while the incorrect positioning with the image intensifier on the opposite side of the surgeon is shown in $\mathbf{b}$ 
Fig. 4 Positioning of the image intensifier and the X-ray tube. The correct positioning with the image intensifier close to the patient is shown in a, while the incorrect alignment with the image intensifier far away from the patient is shown in $\mathbf{b}$

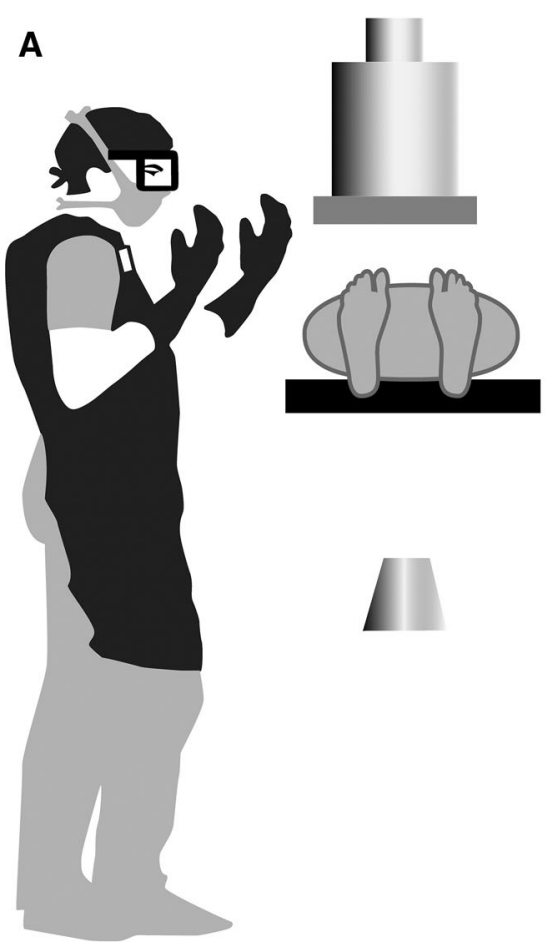

B
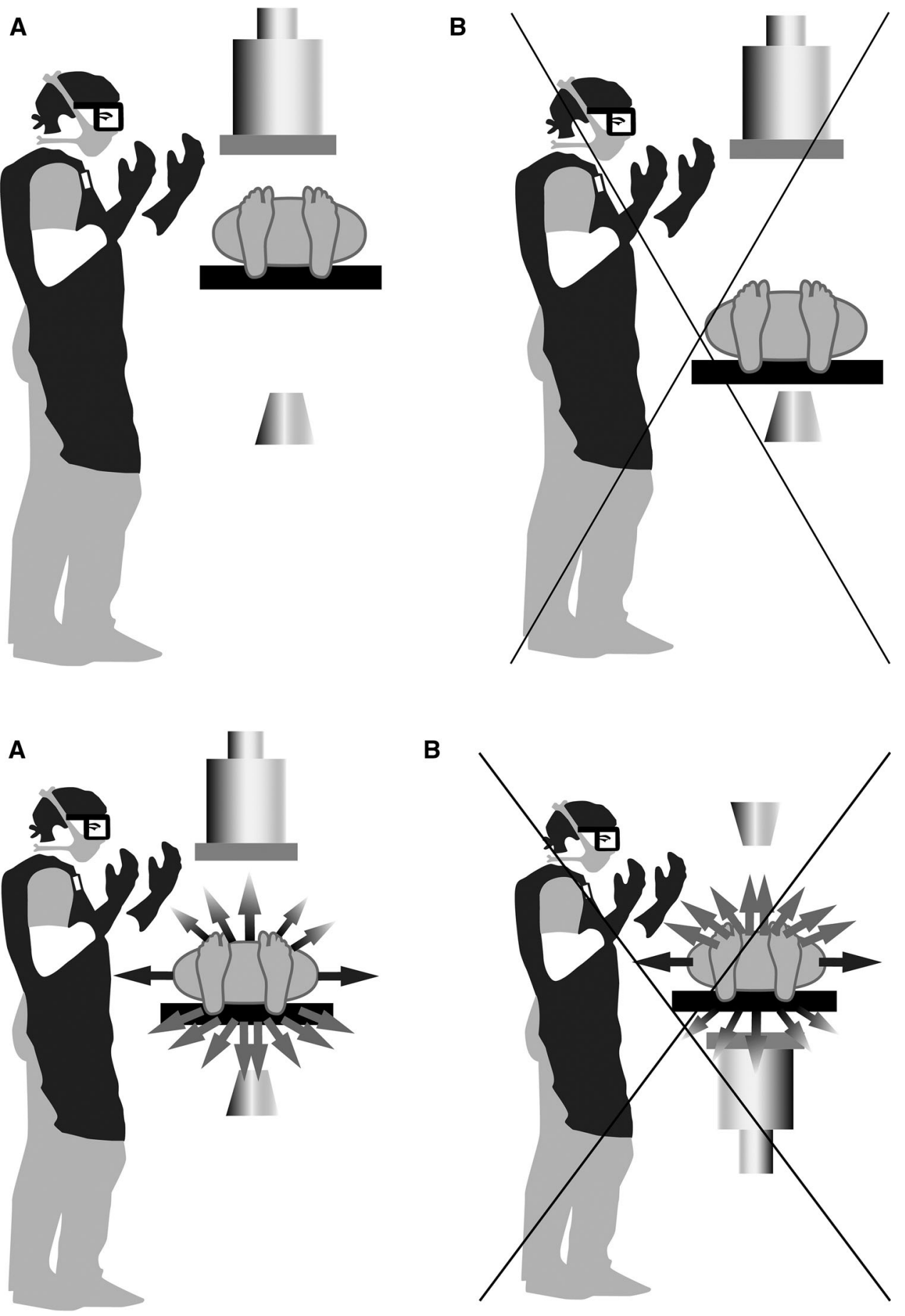

B

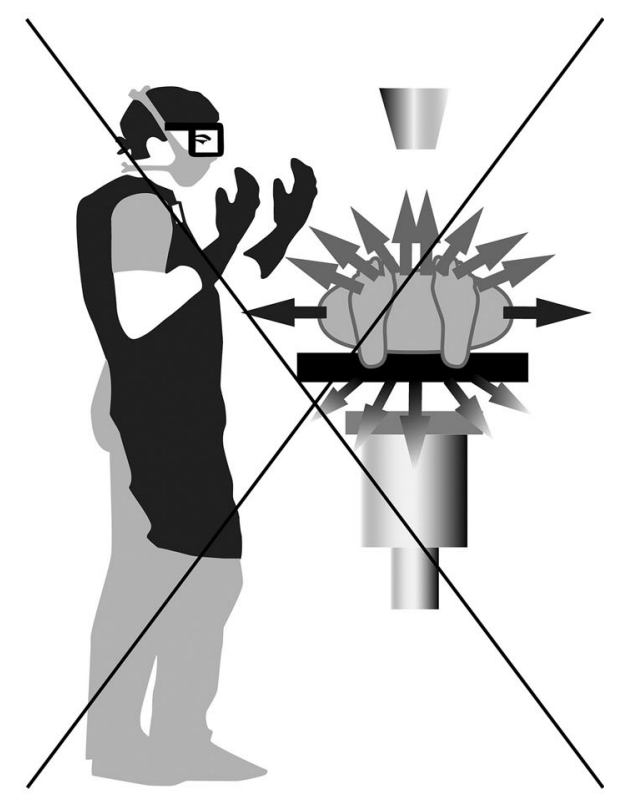

Fig. 5 Vertical positioning of the image intensifier and the $\mathrm{X}$-ray tube. The correct positioning with the image intensifier above the patient is shown in $\mathbf{a}$, while the incorrect positioning with the image intensifier under the patient is shown in $\mathbf{b}$
( $p \leq 0.001)$. Most $(70 \%)$ questions about the knowledge regarding radiation protection were answered similarly by participants with different job positions, but three $(30 \%)$ questions showed significant differences. Firstly, on the question about hand exposure, $85 \%$ of technical assistants, $78 \%$ of lead consultants, $61 \%$ of residents, $40 \%$ of consultants, and $20 \%$ of students correctly answered that the hands are subject to the highest exposure $(p=0.009)$.
Secondly, for the question about collimation, $100 \%$ of lead consultants, $95 \%$ of consultants, $95 \%$ of technical assistants, $75 \%$ of residents, and $60 \%$ of students correctly answered that collimation decreases radiation exposure ( $p=0.043$ ). Thirdly, $95 \%$ of consultants, $75 \%$ of residents, $67 \%$ of lead consultants, $60 \%$ of students, and $57 \%$ of technical assistants correctly answered that the maximal partial body exposure should be $<500 \mathrm{mSv}$ per 
Table 1 Compliance with radiation protection

\begin{tabular}{lccr}
\hline Protection device & $\geq 50 \%$ usage $^{\dagger}$ & $<50 \%$ usage $^{\dagger}$ & Total $^{\dagger+}$ \\
\hline Dosimetry & $36(44 \%)$ & $46(56 \%)$ & $82(100 \%)$ \\
Aprons & $70(84 \%)$ & $13(16 \%)$ & $83(100 \%)$ \\
Thyroid shield & $27(33 \%)$ & $55(67 \%)$ & $82(100 \%)$ \\
Total $^{\dagger}$ & $133(54 \%)$ & $114(46 \%)$ & $247(100 \%)$
\end{tabular}

$\dagger$ The values are given as the number of participants, with the percentage in parentheses

* One participant falsely marked both answers for dosimetry and thyroid shields and was excluded from the corresponding section

year $(p=0.043)$. Lastly, no differences were found between medical doctors and technical assistants for the positioning of the X-ray machine and most $(80 \%)$ of the other questions.

The relatively high percentage $(35 \%)$ of falsely answered questions is interesting because only 169 (20\%) answers were marked as uncertain. The highest percentage of uncertainness was found for the questions about voltage and current $(31 \%)$ as well as the maximal partial body exposure $(30 \%)$, contrarily to the question about collimation (10\%). Mostly (80\%), no associations were found between a correctly answered question and certainness, except for the question about surgery $(p=0.005)$ and maximal partial body exposure $(p=0.029)$.

\section{Discussion}

Intraoperative $\mathrm{X}$-ray duration and volume, the position of the surgeon, patient, and X-ray machine as well as the nature of the surgeon and surgery determine the dose of scattered radiation and, ultimately, radiation exposure [15]. Therefore, radiation protection involves measures against these sources of radiation and exposure as well as targeting technical and staff-related measures such as training [16].

In looking at ways to decrease radiation, the first approach is to start with a reduction in the duration of exposure. The mean X-ray duration in intramedullary nailing is up to $6 \mathrm{~min}$, resulting in an exposure of $1 \mathrm{mSv}$ [17]. Of course, limiting the duration of X-rays to the amount needed to reach a clinical purpose is recommended. This can be achieved by short pedal taps. Saving the last image can prevent unnecessary repetition of $\mathrm{X}$-rays. Intermittent and pulsed fluoroscopy, used to evaluate moving structures, can further reduce radiation exposure and can be useful in kyphoplasties and examination of joint mobility $[18,19]$. Furthermore, keeping the foot pedal with experienced surgeons is helpful in reducing radiation exposure [20, 21].

The second way to decrease radiation exposure is to position the $\mathrm{C}$-arm antero-posteriorly because this is associated with much less radiation exposure than lateral $\mathrm{X}$-rays (Fig. 1). This can be explained by an increased patient volume (size) in a lateral orientation, which leads to increased scattered radiation. The patient volume is also responsible for the fact that radiation exposure is dependent on the surgical procedure. For example, it is up to twelve times higher in internal fixation of the spine [22] compared to nailing of the femur or percutaneous osteosynthesis of the distal radius [23].

The third method of decreasing radiation exposure is to position the surgeon on the side of the image intensifier (mean radiation exposure of $0.02 \mathrm{mSv} / \mathrm{min}$ ) instead of the $\mathrm{X}$-ray generator (mean radiation exposure of $0.53 \mathrm{mSv} /$ $\mathrm{min}$ ) because the image intensifier is able to absorb some of the scattered radiation [22] (Fig. 3). For example, this can decrease the radiation exposure of the thyroid up to fourfold. Unfortunately, this means that residents and
Table 2 Knowledge about radiation protection

\begin{tabular}{lccc}
\hline & Correct answer $^{\dagger}$ & Incorrect answer $^{\dagger}$ & Total number of patients $^{\dagger+}$ \\
\hline Horizontal & $41(49 \%)$ & $42(51 \%)$ & $83(100 \%)$ \\
Vertical 1 & $50(60 \%)$ & $33(40 \%)$ & $83(100 \%)$ \\
Vertical 2 & $50(60 \%)$ & $33(40 \%)$ & $83(100 \%)$ \\
X-ray path & $56(68 \%)$ & $26(32 \%)$ & $82(100 \%)$ \\
Exposure & $50(61 \%)$ & $32(39 \%)$ & $82(100 \%)$ \\
Surgery & $44(54 \%)$ & $38(46 \%)$ & $82(100 \%)$ \\
Voltage and current & $39(48 \%)$ & $43(52 \%)$ & $82(100 \%)$ \\
Collimation & $71(87 \%)$ & $11(13 \%)$ & $82(100 \%)$ \\
Distance & $73(89 \%)$ & $9(11 \%)$ & $82(100 \%)$ \\
Body exposure & $61(74 \%)$ & $22(27 \%)$ & $82(100 \%)$ \\
Total & $535(65 \%)$ & $289(35 \%)$ & $824(100 \%)$
\end{tabular}

$\dagger$ The values are given as the number of participants, with the percentage in parentheses

* The participants, who falsely marked both answer options, were excluded from the corresponding section 
students are often exposed to a 5-times increased radiation because they are mainly located on the opposite side at the $\mathrm{X}$-ray generator [24]. Furthermore, the highest scattered radiation is located on the side where the X-ray beam enters the patient. Placing the X-ray generator under the operating table and the image intensifier over the operating table minimizes the radiation exposure of the radiosensitive eyes and thyroid gland [23, 25] (Fig. 5). Specifically, this maneuver decreases exposure to scattered radiation from $1.2-3.2$ to $0.3-0.8 \mathrm{mSv} / \mathrm{h}[26]$.

The fourth way to decrease radiation exposure is by keeping a greater distance from the patient [27] (Fig. 6). A distance of $0.5 \mathrm{~m}$ is associated with a fourfold decrease in radiation exposure [28]. Doubling the distance from the $\mathrm{X}$-ray machine leads to a fourfold decrease in X-ray exposure because, according to the inverse-square law, radiation is inversely proportional to the square of the distance from the X-ray machine. It was also shown that keeping surgeon's hands at a distance of $15 \mathrm{~cm}$ away from the X-ray beam can lead to a 100 -fold reduction of radiation exposure, which can be achieved with longer instruments [29]. Placing the patient as close as possible to the image intensifier and as far away as possible from the $\mathrm{X}$-ray generator also minimizes scattered radiation [30] (Fig. 4). Doubling the distance between the image intensifier and the patient may lead to a 17 -fold dose increase [15]. Of note, it was shown that keeping a distance of one

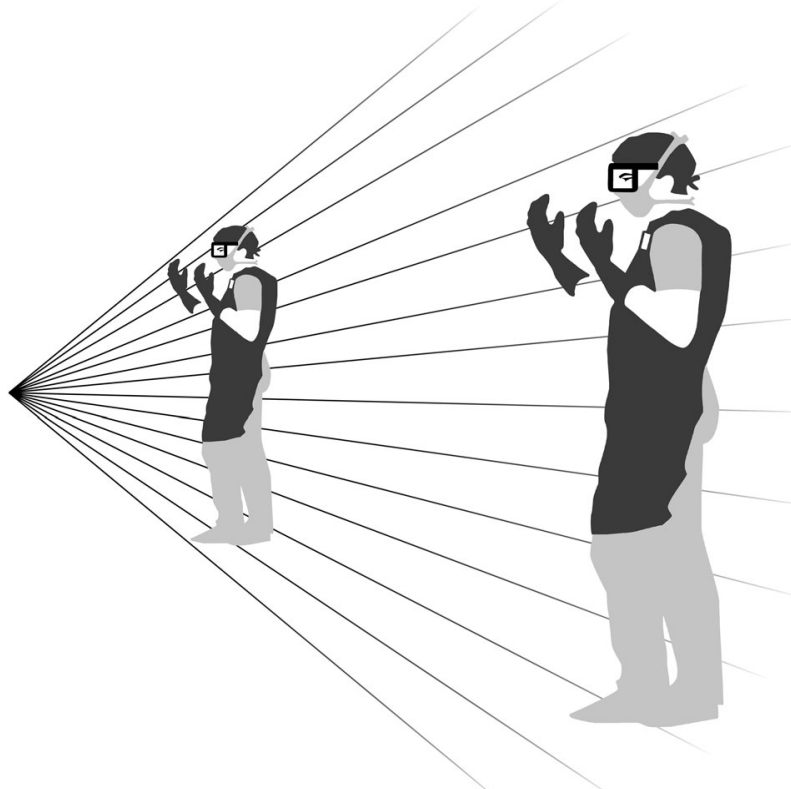

Fig. 6 Reduction of radiation exposure through increased distance from the X-ray source. For example, doubling the distance leads to a decrease in dose rate by 4 , a threefold increase in distance leads to a decrease in dose rate by 9 , and an increase in the distance by factor four leads to a 16 times decrease in dose rate meter from the $\mathrm{C}$-arm resulted in detection of only $0.1 \%$ of scattered radiation while keeping a distance of $2 \mathrm{~m}$ resulted in barely detectable scatter radiation [28]. This led to the opinion that protective wear may not be required in distances of more than $2 \mathrm{~m} \mathrm{[31].}$

The fifth technique to decrease radiation exposure is by collimation of X-ray beams with laser makers for scatter reduction [19]. Larger image intensifiers also lead to less radiation exposure. For example, magnification of image sections can reduce radiation exposure by up to $37 \%$ [15]. Additionally, less radiation is accompanied with a less contrasted image when increasing the voltage and decreasing the current. This is implemented into an automatic dose rate control, which ensures minimal doses with maximal image qualities and is dependent on the tissue density and the presence of metal objects [3, 13, 14]. For example, the dynamic hip screw within the beam may lead to increased radiation exposure [32]. Therefore, it is advisable to turn off the automatic dose regulation once the most important implant positioning has been done.

The sixth method to decrease radiation exposure is accomplished with personal protective devices that minimize radiation. While architectural shielding through walls and equipment-mounted, rolling shields are not useful in the operating room, personal protective devices such as lead aprons minimize radiation exposure [1, 19]. Their usual thickness is $0.25 \mathrm{~mm}$ attenuates more than $90 \%$ of radiation. For example, coverage of the thyroid can lead to a 20-fold reduction of radiation exposure [33]. Furthermore, protective goggles prevent the radiosensitive eye lens from radiation and protective gloves cover exposed hands. Protective gloves may lead to a fourfold reduction in radiation exposure in vertebroplasties [34].

The last, but also very important method of lowering radiation exposure should involve training of surgeons and operating room personnel. An interesting study by Bott et al. [35] has described a way of improving radiation protection by continuing medical education in $\mathrm{C}$-arm positioning with a computer-based training and simulation system. The latter was evaluated by a questionnaire and shown to be helpful in acquiring new knowledge in $79 \%$ of workshop participants $(n=77)$. Various scenarios from an operating room can be used for the interaction with three-dimensional models, which are radiographically reconstructed. Feedback on the trainee's performance on the placement of a C-arm, patient, and table is provided by color graphics, which ultimately leads to a better understanding of scattered radiation and protection against radiation [36]. In contrast to conventional non-interactive didactical methods such as texts and videos, this extended training system offers prompt visual feedback on complex and potentially hazardous radiation facts, which was also described in previous articles by Wagner et al. [37, 38]. Therefore, it may be worth considering the integration of 
these training methods into one's teaching program to enhance the hands-on teaching.

With regard to our study, the relatively low compliance with radiation protection may be overcome by repetitive reminders about the dangers of radiation. Furthermore, the fact that a dosimeter and a thyroid shield are worn more often by trauma surgeons may be attributed to the increased radiation that arises from surgical procedures in the adult trauma setting. Besides, our results about the different use of a thyroid shield between different job positions may suggest that they are worn disproportionally to the amount of X-ray and may indicate a decrease in fear of radiation with more frequent X-ray use because students use a thyroid shield most often, while technical assistants barely used one. On a side note, in contrast to aviation personnel, where the maximal body radiation is usually set at $20 \mathrm{mSv}$ [39], the maximal partial body radiation such as the hands should not exceed $500 \mathrm{mSv}$ per year in trauma surgeons $[1,9,12,13]$ and is even lower for the thyroid gland and eyes. While the radiation exposure to aviation personnel is expectedly calculated [40], trauma surgeons are supposed to wear personal dosimeters. However, this study casts doubt on the compliance with this regulation. In contrast to a about a handful of cases at the interventional cardiology and radiology department, where this limit was broken, trauma surgeons seem not to have reached this limit within the last couple of years. According to the questionnaire of the present study, it remains elusive whether this is due to the actual amount of radiation exposure or lack of compliance in wearing the dosimeter.

The knowledge about radiation protection was improvable in the present study, which may be caused by a lack of structured education about this important topic at regular intervals. The majority of questions were answered similarly by physicians and technical assistants indicating that their knowledge about radiation protection seems to be on a similar level. While medical staff is usually required to partake in educational courses about radiation protection, students may only rely on their knowledge from university courses, which may not address hands-on facts sufficiently enough. Depending on the country, the latter may be true for residents as well. This could be exemplified by their lack of student's knowledge about the beneficial use of collimation, but fairly good knowledge about the maximal partial body exposure per year. However, it must be noticed that the number of students in the present study was fairly low. Therefore, it seems important that the present education may not be enough for everyday tasks of radiation protection and hospitals may consider training the entire staff that uses X-rays at the beginning of a job.

Comparing the falsely answered questions (36\%) with the uncertainly marked (20\%) questions, the discrepancy of $16 \%$ may suggest that participants may overestimate their knowledge about radiation protection, which could potentially be harmful due to an increased radiation exposure. Therefore, medical staff may profit from specific hands-on training in order to avoid unknown mistakes and unnecessary exposure to radiation.

\section{Conclusion}

The compliance with and the knowledge about radiation protection seems to be unnecessarily low in trauma physicians and technical assistants. The discrepancy in falsely answered questions and those marked as uncertain may suggest that participants may overestimate their knowledge about radiation protection, which is potentially harmful due to the increased radiation exposure. Therefore, we advocate a quick and valuable training of trauma surgeons and medical staff addressing the important preventive measures, some of which are illustrated in the present study. These consist of wearing dosimetry and protection devices, reduction in duration, preferable antero-posterior $\mathrm{C}$-arm positioning with the image intensifier close to the patient and the surgeon, as well as maximal distance, collimation, and increased voltage. Furthermore, the use of visual feedback on complex and potentially hazardous radiation facts may be useful for training purposes.

Acknowledgments A modified version of this abstract was accepted as an oral presentation at the DKOU, Congress of Orthopaedics and Traumatology (October 2015), Berlin, Germany. Furthermore, we would like to thank Ms. De-Simio-Hilton for her help with the preparation of the figures.

Conflict of interest The authors declare that they have no competing interests.

\section{References}

1. Singer G (2005) Occupational radiation exposure to the surgeon. J Am Acad Orthop Surg 13(1):69-76

2. Theocharopoulos N, Perisinakis K, Damilakis J, Papadokostakis G, Hadjipavlou A, Gourtsoyiannis N (2003) Occupational exposure from common fluoroscopic projections used in orthopaedic surgery. J Bone Joint Surg Am 85-A(9):1698-1703

3. Oddy MJ, Aldam CH (2006) Ionising radiation exposure to orthopaedic trainees: the effect of sub-specialty training. Ann R Coll Surg Engl 88(3):297-301. doi:10.1308/003588406X98702

4. Maruthainar N, Bentley G, Williams A, Danin JC (2003) Availability of thyroid protective lead shields and their use by trainee orthopaedic surgeons. Occup Environ Med 60(5):381

5. Röntgen KW (1895) Über eine neue Art von Strahlen. Phys Med Gesellsch 9:132-141

6. Uzoigwe CE, Middleton RG (2012) Occupational radiation exposure and pregnancy in orthopaedics. J Bone Joint Surg Br 94(1):23-27. doi:10.1302/0301-620X.94B1.27689

7. Cardis E, Vrijheid M, Blettner M, Gilbert E, Hakama M, Hill C, Howe G, Kaldor J, Muirhead CR, Schubauer-Berigan M, Yoshimura T, Bermann F, Cowper G, Fix J, Hacker C, Heinmiller B, 
Marshall M, Thierry-Chef I, Utterback D, Ahn YO, Amoros E, Ashmore P, Auvinen A, Bae JM, Bernar J, Biau A, Combalot E, Deboodt P, Diez Sacristan A, Eklöf M, Engels H, Engholm G, Gulis G, Habib RR, Holan K, Hyvonen H, Kerekes A, Kurtinaitis J, Malker H, Martuzzi M, Mastauskas A, Monnet A, Moser M, Pearce MS, Richardson DB, Rodriguez-Artalejo F, Rogel A, Tardy H, Telle-Lamberton M, Turai I, Usel M, Veress K (2007) The 15-Country Collaborative Study of Cancer Risk among Radiation Workers in the Nuclear Industry: estimates of radiation-related cancer risks. Radiat Res 167(4):396-416. doi:10. 1667/RR0553.1

8. Herscovici D, Sanders RW (2000) The effects, risks, and guidelines for radiation use in orthopaedic surgery. Clin Orthop Relat Res 375:126-132

9. ICRP (2007) The 2007 Recommendations of the International Commission on Radiological Protection. ICRP publication 103. Ann ICRP 37(2-4):1-332. doi:10.1016/j.icrp.2007.10.003

10. Pinto Dos Santos D, Hempel JM, Kloeckner R, Düber C, Mildenberger P (2014) Teleradiology-update 2014. Radiologe 54(5):487-490. doi:10.1007/s00117-014-2661-3

11. Gundestrup M, Storm HH (1999) Radiation-induced acute myeloid leukaemia and other cancers in commercial jet cockpit crew: a population-based cohort study. Lancet 354(9195):2029-2031. doi:10.1016/S0140-6736(99)05093-X

12. Devalia KL, Guha A, Devadoss VG (2004) The need to protect the thyroid gland during image intensifier use in orthopaedic procedures. Acta Orthop Belg 70(5):474-477

13. Müller LP, Suffner J, Wenda K, Mohr W, Rudig L (1996) Radiation burden to the hands of surgeons in intramedullary nailing. Unfallchirurgie 22(6):253-259

14. Norris TG (2002) Radiation safety in fluoroscopy. Radiol Technol 73 (6):511-533; quiz 534-516, 566

15. Fuchs M, Modler H, Schmid A, Dumont C, Stürmer KM (1999) Measuring intraoperative radiation exposure of the trauma surgeon. Measuring eye, thyroid gland and hand with highly sensitive thermoluminescent detectors. Unfallchirurg 102(5):371-376

16. Dresing K (2011) X-ray in trauma and orthopedic surgery. Physical and biological impact, reasonable use, and radiation protection in the operating room. Oper Orthop Traumatol 23(1):70-78. doi:10.1007/s00064-010-0001-y

17. Sanders R, Koval KJ, DiPasquale T, Schmelling G, Stenzler S, Ross E (1993) Exposure of the orthopaedic surgeon to radiation. J Bone Joint Surg Am 75(3):326-330

18. Ortiz AO, Natarajan V, Gregorius DR, Pollack S (2006) Significantly reduced radiation exposure to operators during kyphoplasty and vertebroplasty procedures: methods and techniques. AJNR Am J Neuroradiol 27(5):989-994

19. Durán A, Hian SK, Miller DL, Le Heron J, Padovani R, Vano E (2013) A summary of recommendations for occupational radiation protection in interventional cardiology. Catheter Cardiovasc Interv 81(3):562-567. doi:10.1002/ccd.24520

20. Botchu R, Ravikumar K (2008) Radiation exposure from fluoroscopy during fixation of hip fracture and fracture of ankle: effect of surgical experience. Indian J Orthop 42(4):471-473. doi:10.4103/0019-5413.43398

21. Noordeen MH, Shergill N, Twyman RS, Cobb JP, Briggs T (1993) Hazard of ionizing radiation to trauma surgeons: reducing the risk. Injury 24(8):562-564

22. Rampersaud YR, Foley KT, Shen AC, Williams S, Solomito M (2000) Radiation exposure to the spine surgeon during fluoroscopically assisted pedicle screw insertion. Spine (Phila Pa 1976) 25 (20):2637-2645

23. Fuchs M, Modler H, Schmid A, Stürmer KM (1999) Strahlenschutz im Operationssaal. Operative Orthopädie und Traumatologie 11:328-333
24. Tasbas BA, Yagmurlu MF, Bayrakci K, Ucaner A, Heybeli M (2003) Which one is at risk in intraoperative fluoroscopy? Assistant surgeon or orthopaedic surgeon? Arch Orthop Trauma Surg 123(5):242-244. doi:10.1007/s00402-003-0516-x

25. Burns S, Thornton R, Dauer LT, Quinn B, Miodownik D, Hak DJ (2013) Leaded eyeglasses substantially reduce radiation exposure of the surgeon's eyes during acquisition of typical fluoroscopic views of the hip and pelvis. J Bone Joint Surg Am 95(14):1307-1311. doi:10.2106/JBJS.L.00893

26. Wolf K, Bohndorf K, Vollert K, Kopp J (1996) Diagnostic imaging and radiation protection in trauma surgery. 2. Unfallchirurg 99(12):975-985

27. Giachino AA, Cheng M (1980) Irradiation of the surgeon during pinning of femoral fractures. $\mathrm{J}$ Bone Joint Surg $\mathrm{Br}$ 62-B(2):227-229

28. Mehlman CT, DiPasquale TG (1997) Radiation exposure to the orthopaedic surgical team during fluoroscopy: "how far away is far enough?”. J Orthop Trauma 11(6):392-398

29. Arnstein PM, Richards AM, Putney R (1994) The risk from radiation exposure during operative $\mathrm{X}$-ray screening in hand surgery. J Hand Surg Br 19(3):393-396

30. Tremains MR, Georgiadis GM, Dennis MJ (2001) Radiation exposure with use of the inverted-c-arm technique in upper-extremity surgery. J Bone Joint Surg Am 83-A(5):674-678

31. Alonso JA, Shaw DL, Maxwell A, McGill GP, Hart GC (2001) Scattered radiation during fixation of hip fractures. Is distance alone enough protection? J Bone Joint Surg $\mathrm{Br}$ 83(6):815-818

32. Goldstone KE, Wright IH, Cohen B (1993) Radiation exposure to the hands of orthopaedic surgeons during procedures under fluoroscopic X-ray control. Br J Radiol 66(790):899-901

33. Tse V, Lising J, Khadra M, Chiam Q, Nugent R, Yeaman L, Mulcahy M (1999) Radiation exposure during fluoroscopy: should we be protecting our thyroids? Aust N Z J Surg 69(12):847-848

34. Synowitz M, Kiwit J (2006) Surgeon's radiation exposure during percutaneous vertebroplasty. J Neurosurg Spine 4(2):106-109. doi:10.3171/spi.2006.4.2.106

35. Bott OJ, Wagner M, Duwenkamp C, Hellrung N, Dresing K (2009) Improving education on C-arm operation and radiation protection with a computer-based training and simulation system. Int J Comput Assist Radiol Surg 4(4):399-407. doi:10.1007/ s11548-009-0322-1

36. Bott OJ, Dresing K, Wagner M, Raab BW, Teistler M (2011) Informatics in radiology: use of a $\mathrm{C}$-arm fluoroscopy simulator to support training in intraoperative radiography. Radiographics 31(3):E65-E75. doi:10.1148/rg.313105125

37. Wagner M, Dresing K, Ludwig W, Ahrens CA, Bott OJ (2012) SIScaR-GPU: fast simulation and visualization of intraoperative scattered radiation to support radiation protection training. Stud Health Technol Inform 180:968-972

38. Wagner M, Duwenkamp C, Dresing K, Bott OJ (2009) An approach to calculate and visualize intraoperative scattered radiation exposure. Stud Health Technol Inform 150:831-835

39. Bundeskanzleramt (2014) Bundesrecht konsolidiert: Gesamte Rechtsvorschrift für Strahlenschutzverordnung fliegendes Personal, Fassung vom 22.08.2014. http://www.ris.bka.gv.at/Gelten deFassung. wxe? Abfrage $=$ Bundesnormen $\&$ Gesetzesnummer $=200$ 04796. Accessed 22 Aug 2014

40. Strahlenschutz Bf (2014) Ionising Radiation $>$ Occupational Radiation Protection > So wird überwacht. http://www.bfs.de/en/ ion/beruf_schutz/methodik. Accessed 22 Aug 2014 